\title{
Toward a Taxonomy of Harm
}

Melissa Adler

madler@wisc.edu

melissa.adler@uky.edu

University of Wisconsin Madison

600 N. Park Street

Madison, WI 53706

Phone: 920.266 .6731

Joseph T. Tennis (corresponding author)

jtennis@uw.edu

The Information School

Box 352840

Mary Gates Hall, Ste 370

Seattle, WA 98195-2840

Phone: 206.685.9937

Fax: 206.616.3152 


\begin{abstract}
When we organize knowledge we act. The wholesomeness of our actions can be measured in the proportion of good or harm they do. How then do we identify and define potential harm in knowledge organization systems? A starting point for contributing to the greater good is to examine and interrogate existing knowledge organization practices that do harm, whether that harm is intentional or accidental, or an inherent and unavoidable evil. As part of the transition movement, the authors propose that we take inventory of the manifestations and implications of the production of suffering by knowledge organization systems through constructing a taxonomy of harm. The aim of our work is (1) to heighten awareness of the violence that classifications and naming practices carry, (2) to unearth some of the social conditions and motivations that contribute to and are reinforced by knowledge organization systems, and (3) to advocate for intentional and ethical knowledge organization practices to achieve a minimal level of harm.
\end{abstract}




\section{Toward a Taxonomy of Harm}

When we organize knowledge we act. The wholesomeness of our actions can be measured in the proportion of good or harm they do. How then do we identify and define potential harm in knowledge organization systems? A starting point for contributing to the greater good is to examine and interrogate existing knowledge organization practices that do harm, whether that harm is intentional or accidental, or an inherent and unavoidable evil. As part of the transition movement, the authors propose that we take inventory of the manifestations and implications of the production of suffering by knowledge organization systems through constructing a taxonomy of harm. The aim of our work is (1) to heighten awareness of the violence that classifications and naming practices carry, (2) to unearth some of the social conditions and motivations that contribute to and are reinforced by knowledge organization systems, and (3) to advocate for intentional and ethical knowledge organization practices to achieve a minimal level of harm. We do not aim to be prescriptive, but rather, we will describe many of the consequences of present knowledge organization systems, with the hope that it will stimulate and support corrective efforts.

\section{Theoretical Underpinnings}

The theoretical underpinnings of the taxonomy of harm derive from Žižek, Foucault, and Haraway, and Arendt who explore the semantic violence imposed by language and categories, as well as Buddhist teachings on harm and suffering. Drawing from Donna Haraway and Buddhist tenets on co-origination and mutual reinforcing ontology, we find wholesomeness, or interconnectedness, to be a central component in theorizing our taxonomy of harm. We recognize and commit to the ontological position that developing, maintaining, and using knowledge organization systems are acts in constant motion which stand in relation to others. 
Such systems, as tools we create, are always becoming together in mutually defining and reinforcing relationships. Classifications, those who classify, and those being classified are coconstitutive. At the same time, the use of language can often be a violent act and classifications always have the potential to inflict some degree of damage. Given this seemingly inescapable truth we ask, following Haraway (2007), "What might a responsible 'sharing of suffering' look like in classification and naming practices?" As knowledge workers, we have a responsibility to do the least harm possible.

Hannah Arendt believed that, in order to understand how violence works, we must be careful not to conflate violence with the concepts of power and authority. "Indeed one of the most obvious distinctions between power and violence is that power always stands in need of numbers, whereas violence up to a point can manage without them because it relies on implements. A legally unrestricted majority rule, that is, a democracy without a constitution, can be very formidable in the suppression of the rights of minorities and very effective in the suffocation of dissent without any use of violence (41-42).

For Arendt, violence is distinguished from power by its instrumental character, with tools designed and used to increase strength. Power derives from a group of people acting in concert; a majority rule can suppress rights of minorities without tools, she argues (44-45). Authority can be vested in persons or in offices. "Its hallmark is unquestioning recognition by those who are asked to obey; neither coercion nor persuasion is needed" (45). What we hope to do here is show that bibliographic tools, particularly language and classifications, can be used as instruments of violence. "Violence, being instrumental by nature, is rational to the extent that it is effective in reaching the end that must justify it. And since when we act we never know with any certainty the eventual consequences of what we are doing, violence can remain rational only if it pursues 
short-term goals. (Arendt, 79) These are never neatly compartmentalized, so institutionalized power often appears in the guise of authority. Haraway observes that pain is often caused by an instrumental apparatus and is not borne symmetrically. Rather, those in positions to wield the apparatus have more control over actions and their effects. For our purposes, we view classification systems to be instrumental apparatuses capable of systemic and symbolic violence. Žižek (2008) outlines three kinds of violence - subjective, objective, and symbolic. Here we are interested in ways that language produces violence, which is primarily a symbolic form of violence. Žižek identifies a "direct link between the ontological violence [creating things in the world] and the texture of social violence (of sustaining relations of enforced domination) that pertains to language" (71). He suggests that the violence in the human ability to speak resides in its function of "othering" people, including our closest neighbors, which inherently leads to oversimplification and division. As Tennis (2013) has pointed out,

objective violence can surface in our work, because our work is rooted in what Žižek calls symbols and systems. First, we use the symbolic systems of language and its more refined subset of indexing languages - often controlled indexing languages. And we operate within systems, as defined by Žižek that are part of the socio-political system legitimated as components to help the (capitalist) democratic citizen (45).

Manifestations of objective violence can take on multiple forms, with myriad consequences. The present project is a move toward identifying symbolic and systemic violence in $\mathrm{KO}$.

We invoke Ron Day's critical research in information studies to illustrate ways that violence can materials in information work. Day (2011) calls for a critical evaluation of our present networked information society, which has produced an increased need for "the 
transmission and inscription of 'clear' statements and the establishment of common classification structures, cataloging terms, and technical linking protocols" (25-26). According to Day, flattened hierarchies have brought more freedom for knowledge workers in the workplace, with the cost in restriction of the worker's freedom of expression. We take this to be an example of symbolic violence.

Day's account of the production of needs by information systems serves as an illustration of systemic violence. He has concluded that the core traditions of information science are defined by the psychology of need, which is "based on a normative psychology of cultural forms and social situations, constructed by analyzing language vocabulary and other semantic markers and social associations" (Day 29). Information systems produce users and needs, rather through taking advantage of and shaping social dynamics through algorithmic functions.

Much of Foucault's work interrogates the normalizing effects of disciplinary systems, which serve to correct deviant behavior by coercing citizens to live according to society's standards or norms. Discipline and Punish reveals how techniques and institutions have converged to create the modern system of disciplinary power, which situates individuals in a field of documentation, as results of exams are recorded in documents that provide detailed information about the individuals examined and allow power systems to control them. On the basis of these records, those in control can formulate categories, averages, and norms that are in turn a basis for knowledge. Viewed in this light a knowledge organization system is an instrument of documentation that carries disciplinary power. At the same time it provides evidence of the position from which people and institutions classified others or have become categories. 
We are also speaking directly to Feinberg's $(2011,2007)$ research on classifications as situated knowledges, authority and voice, and morality by reflecting on the positionality from which people classify and the moral obligations we have in subject creation. We are also building upon Olson and Schlegl's (2001) meta-analysis of subject access, in which they delineate treatments of topics as exceptions to a norm. Bowker and Stars' (2000) research unmasks classifications as hidden infrastructures that carry meaningful consequences in the lives of those who are classified and who fall outside of social norms.

These theoretical underpinnings inform our work, and guide our ontological commitment, recognition of the problem of harm in knowledge organization systems, and guide our decisions about how to organize the taxonomy of harm.

Harm is apparent to us when we deviate from agreed upon set of precepts that dictate what is ethical. If we agree that there are particular precepts in the field of knowledge organization we can then decide as a community what is ethical and what can be interpreted as causing harm. Elsewhere we have proposed some precepts which may be useful in this discussion (Tennis, 2013). These precepts can be interpreted as being prescriptive to a point, but in an effort to align our theoretical position with Buddhist ethics, we also assume a non-dualistic position that prescribes, but in a particularly impermanent and contextually sensitive manner. 


\section{Organizing principles}

The most appropriate structure for a taxonomy of harm is open to discussion.

Furthermore, the authors recognize their positions of privilege and the risks that naming conditions and concepts carry. To name is to wield some degree of power, and to organize any part of the universe is, to a lesser or greater degree, a coercive act. With that in mind, we believe this project is imperative. What we are naming and organizing are acts, actors, and effects of harm. To call these acts out and name them is to bear witness to suffering, to hold organizers of information accountable and reveal ways in which we are complicit or willing participants in reproducing harm, and to begin to take inventory of the weightiness of classification and categorization. We also acknowledge the limitations of language to describe suffering; our taxonomy here will be constrained by language and categories, just as classifiers of all sorts struggle to fit ideas, affects, and effects into words. Nevertheless, we must try and recognize that this taxonomy is intended to be amended, rearranged, and corrected. We call upon the community of knowledge organizers to reach a sort of consensus on what constitutes harmful acts and what might be done, knowing that debate will always surround many of the concerns we raise here. The classified and the classifier are mutually constitutive; beings are always becoming together in relationships.

The act of calling something into being by name is to done as a witness who stands in a particular position. There are at least three levels on which classifiers bear responsibility: A) to name those conditions that remain unsaid or unnamed, particularly with regard to suffering; B) to recognize their positionality with respect to that being named; and C) to classify with intentionality toward justice and doing the least harm. By naming phenomena, events, or groups of people we are providing evidence of witnessing. 
The taxonomy of harm will be organized around three main questions, which each have intersecting concerns as are described below. We ask A) What happens? B) Who participates? and C) Who is affected and how?

\section{What happens?}

In order to examine what happens when we classify, we operationalize tenets of Buddhism to apply it in everyday practice of knowledge workers. We must consider (1) actions, (2) the wholesomeness of these actions, (3) the intentionality with which the actions are carried out, and (4) the implications of those actions. It is important to acknowledge that harm is installed. All knowledge organization systems are potentially harmful, and the consequences might vary greatly depending on perspectives (Tennis, 2012).

\section{Actions}

Following Olson and Schlegl's (2001) analysis of literature on bibliographic subject standards, we are locating harmful actions by looking for cases of exceptionalism, ghettoization, omission, inappropriate structure of the standard, biased terminology, erasure, and pathologization. Each of these can be understood as problems of normalization or disciplining. And what classifications do, particularly for groups of people, but also across the disciplines and on range topics, is reproduce and reify norms.

Treatment of a topic as an exception occurs when something "is represented as being outside of some accepted norm" (Olson and Schlegl 2001, 67). [this seems like an umbrella category for omission/ghettoization/bias, doesn't it?] “Ghettoization is the problem of gathering and then isolating a topic rather than integrating it....indicative of the practice of considering disturbing ideas as other to be set aside, outside of the mainstream" $(67,69)$. "Omitting a topic is often a problem of the lack of currency of subject access standards, but may also be a problem of 
underlying assumptions" (Olson and Schlegl, 68) We suggest adding erasure as an harmful action, distinguishing it from omission. Erasure suggests greater purposiveness, the removal or covering up of something that was once there, rather than simply leaving it out. The reparative processes are slightly different, i.e., to counter omission we would write something into the story, as historians have given voice in recent decades to those left out. To overcome erasure requires a restoring or recovering. For example, Google just removed the word bisexual from its block list. It was there until the fall of 2012. This had rendered and entire community invisible because of the far reach of Google. It was present and then erased, and in order to repair the situation someone needs to recover the term. We also add pathologization as a particular form of bias when classifications serve as a sort of diagnosis and reproduce medicalized norms.

All of these categories are connected; for instance, some of the ghettoization may result from the structure of standard, as illustrated by LCSH. This is a system in which categories are marked and unmarked, and within the unmarked categories are, implicitly, all of the groups that have yet to be named as well as those that do not require a name because they are assumed to be normative. The heading "Women accountants" is a typical case. There is no need for a heading "Male accountants," because maleness is the norm. "Asian American bisexuals" is another kind of case. There are at least two components, "Asian Americans" and "bisexuals," and both of these arose as marked categories. To illustrate the point, we do not find "Asian American heterosexuals" or "Caucasian bisexuals." Such marked categories set up a binary opposition of what something is and what something is not.

\section{Wholesomeness}

“living well, flourishing, and being 'polite' (political/ethical/in right relation) means "staying inside shared semiotic materiality, including the suffering inherent in unequal and ontologically multiple instrumental relationships." (Haraway, 72) 
In consideration of wholesomeness we ask how these subjects are constructed in relation to others and to the knowledge workers producing them. Subjects are response-able: "responsibility is a relationship crafted in intra-action through which entities, subjects and objects, come into being" (Haraway 71) According to Buddhist principles, the pair of notions crucial to the study of Right View is that of subject and object. The world is an object of the mind. "Subject and object manifest together at the same time and depend on each other" (Hanh, 75). Interbeing in everything. "How we view the world affects everything within it" (Hanh, 76). Failing or refusing to come face-to-face reduces our ability to recognize the extent of our relations and how our acts affect others and ourselves. We might also think in terms of the Buddhist notion of karma. One does not act in isolation when one produces or applies a system, and the classificationist bears a responsibility to do the least harm. Actions carried out with wisdom, compassion, and awareness of others are beneficial to those who are classified, as well as the classifiers and the world.

\section{Intentionality}

"According to the First Noble Truth, we need to call our suffering by its true name. Once we have named what is causing us to suffer, we are more able to look deeply into each suffering in order to find a way to transform it." (Thich Nhat Hanh, Good Citizens, 31)

Intentionality is a essential component in understanding what happens, as one may intentionally perform an evil act knowing that it is evil and will cause harm, one may produce suffering not knowing that the action is wrong or will cause harm, or one might cause suffering simply by accident. The purposefulness of the action depends to a great extent on intent, and this should have bearing on the meaning of the action. This matters because most acts of knowledge organization are not performed with an intent to harm. In unmasking our role in causing harm when we classify, it is hoped that we will inspire a will to more intentionally do the least harm. 
Tennis has identified five levels of intentionality and two measures of knowledge of acts, which combined, can guide the ethical considerations of actions. "Intention for our purposes is: performing an action for a specific purpose. If we want to believe we are doing good work, then we have to believe our intentions are good" (Tennis).

A critical objective of this project is to call out to classifiers and invite them to reflect on their intentions when they perform an organizing act. We will not speculate as to the intentions of producers or users of classifications, but rather, we ask knowledge organizers to consider their own intentions when they act.

\section{Implications}

"Far from making us more knowledgeable and careful toward other beings, information can give us a comforting stupidity." (Day 29)

Implications include questions of morality, types of effects, and why these consequences matter. Again, Haraway and Buddhist tenets will guide us in observing implications. The question of implications remains open and will continue to reveal themselves. We can offer a starting point for considering some of the implications of this project.

Olson and Schlegl have concluded from their intertextual reading of the subject access literature that "our focus on users, our quest for objectivity, and the standardization we use to achieve these goals may be at least partly responsible for our systemic problems" (Olson and Schlegl, 62). In service to these goals, subject tools have contributed to larger systemic and symbolic conditions. Smith (1999) implicates classification systems as central to imperialist discourses. She writes, "The collective memory of imperialism has been perpetuated through the ways in which knowledge about indigenous peoples was collected, classified and then represented in various ways back to the West, and then, through the eyes of the West, back to those who have been colonized" (1-2). Classifications present ideologies and attitudes, 
depending upon the lens through which a classifier views the world. In the case of imperialism, various legitimatizing discourses play out, including those of salvation, economics, and health.

Of course, there is the central question of access to information. By way of objective, standardized, and "user"-centered categories (which, according to Day, effectively produce users and their needs), our systems and terminologies fundamentally impede access to resources.

\section{Who participates?}

If we follow the stance of co-origination, then no one escapes responsibility in the production of knowledge organization systems. Clearly, the people and agencies who create classification systems carry power in relation to those being classified and those using the system. However, if we take it to be true that such systems are always becoming together with those who produce, use, and give meaning to the systems, we must ask about the agency and influence of the classified and the consumers of the systems. Is there a dialogue, resistance, or common ground among the classifiers and the classified?

Participants hold varying degrees of power. Those who creating and structuring a system or authorize names and categories wield greater power than those who select from existing systems and apply already authorized categories or from those who recycle already produced metadata. At every level, though, there is an opportunity to call one's actions into question, to ask whether the given name is the ethically sound choice. Ethically speaking, the optimal choice may be to reject what is offered, to refuse or elicit change, or even to remain silent.

\section{Who is affected?}

Those affected may be individuals, groups, nations, and any configuration of individuals who are served by or are somehow in service to a classification system. We will not be able to examine every instance of harm or every group or individual harmed. The goal is to recognize 
the processes and implications so that we can apply this awareness when we construct subjects in particular contexts with the intention of serving those constituencies well.

\section{Who participates}

Cultural institutions

Individuals

Communities

Nations

Governing bodies

Administrative agencies

Military

Industry

Legal institutions
Actions

Ghettoization

Exceptionalism

Inappropriate structure

Bias

Erasure

Omission

Pathologization
Who (what) is affected

Communities

Nations

Individuals

Nature

Here we present two examples of how classifications do harm:

Adler (2012) has conducted an intellectual history of the Library of Congress Subject Heading, "Paraphilias," which was authorized in 2007 to replace "Sexual deviation." The result of this work is an understanding of the processes and consequences at work with heading. In terms of our taxonomy of harm, we ask who participates in the creation and assignment of "Paraphilias," what actions are in play, and who is affected.

At the institutional level, "Paraphilias" was authorized by the Library of Congress, a large governmental cultural institution. LC catalogers chose this term based on medical/psychiatric literature, stating that the heading is more neutral than other alternatives, such as deviation or perversion. On both a global and local level, though, this heading is reproduced and circulated to libraries of all types and sizes around the world. Librarians adhering to cataloging and classification standards add this heading to bibliographic records or download records that include the heading from shared catalogs such as WorldCat. 
We identify three key actions: bias, erasure, and pathologization. By drawing from the psychiatric literature, catalogers have implicitly accepted the assumption that certain sexual behaviors and expression are medical concerns. The heading is applied to works in the humanities and social sciences, which generally resist medicalizing discourses. By imposing medicalized language onto works that do not use such terminologies, there is a form of erasure, a refusal to allow the literatures speak on their own behalf.

Those most directly affected are the people that would consult a catalog to find materials assigned this heading. Those who produce or read texts and reside outside of the psychiatric discipline, in particular humanities and social science scholars and public library patrons, will not only be underserved by the heading, but are also subjected to a pathologizing term. For example, the book description for Part-time Perverts: Sex, Pop Culture, and Kink Management published by Praeger in 2011, reads:

An interdisciplinary exploration of sexual perversion in everyday life. Drawing on her own experience, as well as on pop culture and a multidisciplinary mix of theory, the author shifts the discussion of perversion away from the traditional psychological and psychiatric focus and instead explores it through a feminist lens as a social issue that affects everyone.

Despite the clearly stated aim to position alternative sexualities outside the medical establishment and inside an interdisciplinary field of cultural studies, the only subject headings applied to the bibliographic record for this book are "Paraphilias" and "Sex customs." The author has no recourse, other than to petition LC to drop or change the medically derived heading. The act of naming, in this case, ignores the author's stated objective and disciplines the work by situating it in psychiatry.

The implications of the heading are too expansive to detail here. The most direct effect is the limitation on access to information, as an obscure medical term is used to provide subject 
access for materials in a range of disciplines outside of psychiatry. But what is at stake here is much more than access to information, as this heading ultimately serves to reproduce dominant discourses concerning normal and abnormal sexualities. Inherent in the authorization of this word are histories of power, normativity, and citizenship borne out of state-defined notions of health.

The heading presents an almost paralyzing ethical dilemma. Is it better to have no heading at all that groups "deviant" sexual behaviors together? If we do use a term, what should it be? What are our intentions when we use this word? If it is to provide access, we are failing. It is unlikely that any librarian has set out to reproduce discriminatory or negatively biased assumptions.

The concept and field of eugenics can give us another example of harm. Eugenics is a term that first appears in the Dewey Decimal Classification in 1911. At that time it is considered a biological science. As of the 1950s it is no longer possible for a classifier to place a book primarily on eugenics in the biological sciences. The other options are social sciences, applied sciences, and philosophy and ethics. And while eugenics has a diverse set of related fields, ranging family planning to anthropometry, we see a different kind of erasure here. This is especially true since eugenics is still used in population genetics work, albeit there is an open debate about what counts as eugenical work and thought (Paul, 1995). Yet even with that debate population genetics is squarely a biological science, so the erasure here seems to be more about avoiding a term that might have negative consequences when in fact it is the term used in the literature.

Along with erasure another action taken is inappropriate structure. If we relegate eugenics to applied sciences then we are not situating literatures on this aspect of population 
genetics in with other aspects of evolutionary biology specifically or biology generally. Finally, the relationship between old classes and new classes in successive editions of a scheme, used in the same collection causes another form of inappropriate structure, the where materials classed under older and now outdated class numbers occupy a strange position in relation to biological texts. In the case of eugenics we see materials with this subject in the same class as those that have the reproductive parts of plants as their primary topic. The ethical concerns here is the harm caused in misrepresentation - severing the cord to the earlier appearance of the concept.

\section{Conclusion}

Haraway (2007) has stated that to live well means "staying inside shared semiotic materiality, including the suffering inherent in unequal and ontologically multiple instrumental relationships" (72). In working toward a taxonomy of harm we will get inside classification systems and realize and share the effects of knowledge organization systems, with the awareness that we have a responsibility toward the subjects that we organize. By witnessing some of the harmful effects of classifications we can continue to transition toward doing the least harm and the greatest good. 


\section{References}

Adler, Melissa. 2012. For SEXUAL PERVERSIONS see PARAPHILIAS: disciplining sexual deviance at the Library of Congress (Doctoral dissertation, Ph. D. dissertation, University of Wisconsin, Madison. UMI).

Arendt, Hannah. 1970. On Violence. Orlando: Harcourt.

Bowker, Geoffrey and Star, Susan Leigh. 1999. Sorting things out: Classification and its consequences. Cambridge: MIT.

Day, Ron E. 2011. The episteme of information and the place of need: The contributions of (L)IS. Keynote talk for the Post-Graduate Program in Information Sciences of the Universidade Federal Fluminense's (Rio de Janeiro, Brazil) Seminar on Information Studies, September 26, 2011

Day, Ron E. 2001. Totality and representation: A history of knowledge management through European documentation, critical modernity, and post-Fordism. Journal of The American Society for Information Science and Technology 52: 725-735.

Feinberg, Melanie. 2007. From hidden bias to responsible bias: An approach to information systems based on Haraway's situated knowledges. Information Research 12 (4), October, 2007.

Feinberg, Melanie. 2011. Organization as expression: classification as digital media. In Bill Aspray and Megan Winget (eds), Digital media. Scarecrow Press.

Haraway, Donna J. 2007. When species meet. Minneapolis: University of Minnesota Press.

Nhat Hanh, Thich. 2012. Good citizens. Berkeley, CA: Parallax.

Olson, Hope A., and Rose Schlegl. 2001. Standardization, objectivity, and user focus: A metaanalysis. Cataloging \& Classification Quarterly 32(2) 61-80. 
Adler, M., \& Tennis, J. (2013). Toward a Taxonomy of Harm. NASKO, 4(1).

Retrieved from http://journals.lib.washington.edu/index.php/nasko/article/view/14641

Paul, Diane. (1995) Controlling Human Heredity” 1865 to the present. New Jersey: Humanities Press.

Smith, Linda Tuhiwai. (1999) Decolonizing Methodologies. London: Zed Books.

Tennis, Joseph T. 2013. Ethos and ideology of knowledge organization: Toward precepts for an engaged knowledge organization. Knowledge Organization. 40.

Žižek, Slavoj. 2008. Violence. New York: Picador. 